\title{
Our energy future starts from actual energy limits
}

\author{
Gianluca Alimonti \\ INFN and Università di Milano - Via Celoria 16, Milano, Italy
}

\begin{abstract}
Summary. - Since the discovery of fire, the history of human evolution reflects the history of mankind's ability to control and transform energy. Steam engine gave rise to the industrial revolution and fossil fuels entered and shaped our development: diffused and cheap energy allowed to replace human labor, and activities, impossible until that time, became common. Nowadays more than $80 \%$ of the global primary energy consumption comes from fossil fuels, but this energy system has limitations: green house gases and polluting emissions are generated by the fossil fuels combustion. Moreover fossil fuels are limited energy resources and sooner or later they will run out. It is thus important to start shaping and building a new energy system and this is what this school is about.
\end{abstract}

The history of energy, evolution and discoveries in transforming energy, is the history of mankind. This is the case starting from the Prometheus mythology who gave fire, the first energy technology that transforms chemical bonds to thermal energy, to mankind, to Newcomen\&Cawley, inventors of the steam engine.

The relationship between energy and human evolution has historically been very close and it is still very important, as shown by the Human Development Index (HDI). Such an indicator has been defined by the United Nations Development Program to emphasize that people and their capabilities should be the ultimate criteria for assessing the development of a country, not economic growth alone.

The HDI is a summary measure of the average achievement in key dimensions of human development: a long and healthy life, being knowledgeable and have a decent 


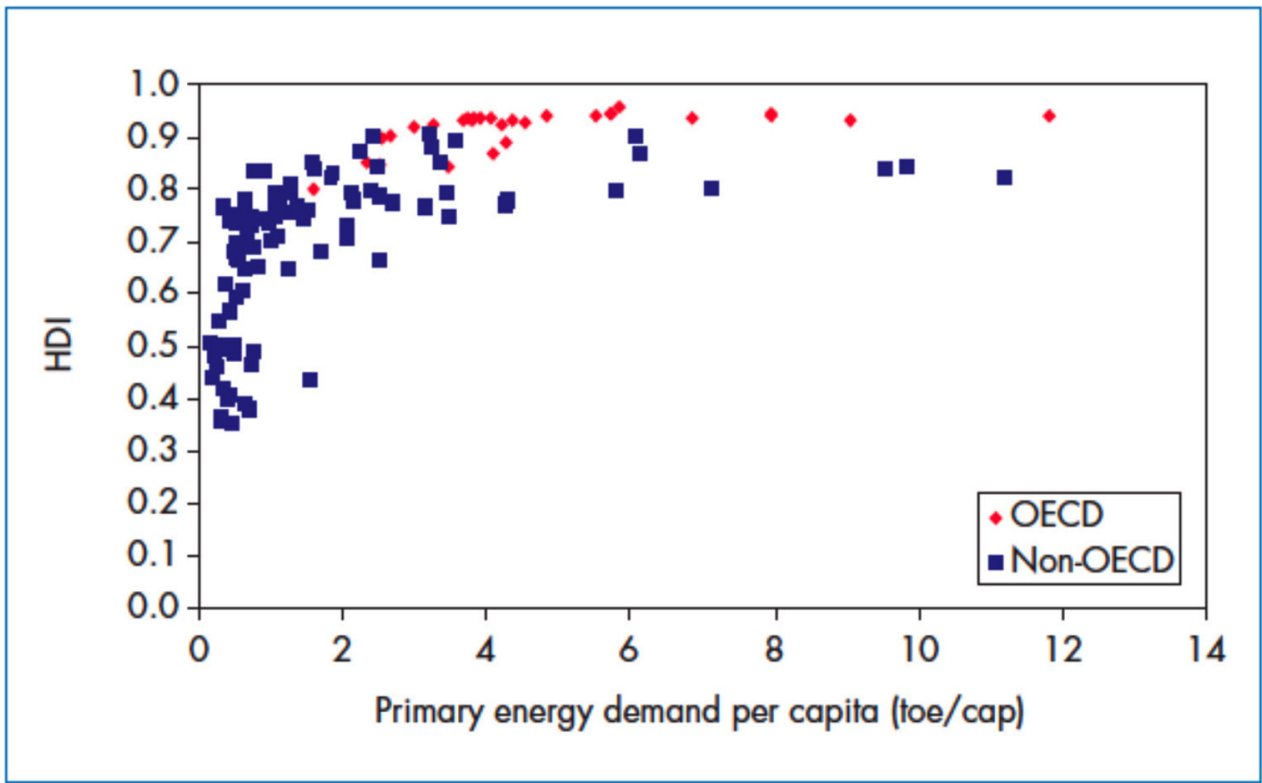

Fig. 1. - HDI and primary energy demand per capita, 2002. (Courtesy of IEA.)

standard of living. The HDI is the geometric mean of normalized indices for each of the three dimensions.

As shown in fig. 1, coming from an International Energy Agency (IEA) analysis, there is a clear relationship between HDI and primary energy demand per capita [1], with OECD countries all being in the high part of both HDI and energy use. After a steep increase, once you hit OECD country levels of per capita energy consumption, the HDI does not appear to increase much, but lower energy consumption has an impact.

As we all know, energy can neither be created nor destroyed, but only transformed into the many different thermal, mechanical and chemical forms we are used to. Depending on the form, a different unit is generally used, but with simple equivalences it is possible to go from electron volts, to joule, from calories to tons of oil equivalent $\left({ }^{1}\right)$.

Never mix energy with power: assuming a FIAT 500 has the same weight of a Ferrari, there is not a big difference indeed, they both have the same energy when travelling at the same speed even if, given the different power they have, they may need different time to reach the same velocity.

Energy is related to power the same way length is related to velocity or the amount of water in a dam with the incoming/outgoing water flux or, for people having a more economic background, money in a bank account is related with salary and expenses!

$\left({ }^{1}\right)$ A very useful unit converter can be found at https://www.iea.org/statistics/ resources/unitconverter/. 
Just to give few examples, we go from few watts of a modern LED light, to about $1 \mathrm{~kW}$ of an oven, from about $100 \mathrm{~kW}$ of a car up to few MW of a train.

With simple calculations, assuming we use all the energy we consume in one day with a standard diet, we can evaluate that the average power of a human body is about $100 \mathrm{~W}$ or that a hydroelectric plant has to convert the potential energy of 1 ton of water falling from about 367 meters (assuming an ideal conversion efficiency equal to 1 ) to produce just $1 \mathrm{kWh}$. Similarly, we can calculate that the energy content of 10 grams of wood would ideally be enough to lift a man by more than 100 meters and the energy content of a 100 grams chocolate bar would lift the same man by about 2000 meters!

Primary energy is the energy directly available in nature.

There are renewable primary energy sources (or simply renewable energy sources, RES) like hydroelectric plants but also ocean energy sources, wind, solar, biomass; part of the urban solid waste, as a biomass, is also considered a renewable energy source. All RES come directly or indirectly from the Sun and as such they are considered to be unlimited.

The fossil energy sources like oil, coal and natural gases like methane are the most important primary energy sources: they also come from the Sun but their generation time is much longer than the one of RES and they cannot be considered renewable energy sources. Energy from nuclear fission, not generated by breeder reactors, is in this same group of limited primary energy sources.

Some authors define a third group: the "almost unlimited" primary energy sources. Among these we can find nuclear energy generated by breeder reactors (that will be described in a dedicated paper) and, hopefully in the future, by fusion reactors. Also geothermal energy, being generated partly by the radioactive decays inside our planet and partly by the fossil heat remaining since the formation of Earth, is not, strictly speaking, a RES and it is listed among the "almost unlimited" primary energy sources. More often though, geothermal energy is considered a RES and fission, even if from breeder reactors, and fusion are considered in the group of "not renewable" primary energy sources.

Primary energy sources are generally transformed into secondary energy sources or energy carriers that are more suited to transport and/or final use. Unfortunately every time there is an energy transformation, there is an energy loss.

An example of secondary energy is electricity: it has the huge advantage of being easily transportable over great distance to the final user, who can very easily convert it with very high efficiency into mechanical energy, heat, use it as light source or in many different and common ways.

Electricity has the drawback that it cannot be stored in significant amount and for long time and therefore must be produced at the same time of the request: this is, as we will see during this school, an important limit that is causing more and more stringent problems for the grid stability. To solve such a limit, important developments on electricity storage are going on, and the grid stability problem may partly be addressed by the development of smart grids that will be presented during this week.

Let us now consider the energy to the final consumption and its link with the primary energy sources. 
If we have $1 \mathrm{~kg}$ of dry wood having about $4 \mathrm{kWh}$ of primary energy in the form of chemical bonds and we burn it in a stove to heat a room, we then have $4 \mathrm{kWh}$ of energy to final consumption.

Starting again from the same primary energy in the form of dry wood, but converting it into electricity burning the wood in a thermoelectric power plant with an efficiency of $25 \%$, we will then have just $1 \mathrm{kWh}$ of electricity to the final consumption and $3 \mathrm{kWh}$ of primary energy will be lost. There are thus $4 \mathrm{kWh}$ of energy to the final consumption in the first example and just $1 \mathrm{kWh}$ in the second example, but in both situations they derived from the same primary energy of $4 \mathrm{kWh}$. The question is: what amount of primary energy can be associated to $1 \mathrm{kWh}$ produced by a hydroelectric plant? (the same question applies to the energy produced by photovoltaic or wind power).

This is not a difficult question, but the answer is not unique as can be seen comparing the world primary energy production data [2] given by the International Energy Agency (IEA) with the same data [3] coming from British Petroleum (BP): IEA is reporting a hydroelectric primary energy that, up to a few years ago, is about one third of the nuclear primary energy (both hydroelectric and nuclear produce only electricity and until the Fukushima nuclear incident they were producing about the same amount of electricity). On the other hand, BP is reporting an almost equal primary energy production for these two energy sources, as it is for the produced electricity. The reason for this difference are the different conventions for electricity.

According to IEA, figures for electricity production, trade, and final consumption are calculated using the energy content of the electricity (i.e. at a rate of $1 \mathrm{TWh}=$ $0.086 \mathrm{Mtoe}$ ). Hydro-electricity production (excluding pumped storage) and electricity produced by other non-thermal means (wind, tide/wave/ocean, photovoltaic, etc.) are accounted for similarly using $1 \mathrm{TWh}=0.086 \mathrm{Mtoe}$. However, the primary energy equivalent of nuclear electricity is calculated from the gross generation by assuming a $33 \%$ conversion efficiency, i.e. $1 \mathrm{TWh}=(0.086-0.33)$ Mtoe. For geothermal and solar thermal, if no country-specific information is reported, the primary energy equivalent is calculated as follows:

- $10 \%$ for geothermal electricity;

- $50 \%$ for geothermal heat;

- $33 \%$ for solar thermal electricity;

- $100 \%$ for solar thermal heat.

It is very important to understand the used conventions because they may have concrete impacts: as an example, the RES European targets are defined in terms of energy to the final consumption, while the efficiency European targets are based on primary energy consumption.

From figs. 2 and 3, taken from the IEA publication "Key World Energy Statistics" 2016 [2], it can be seen that the world primary energy supply has more than doubled 


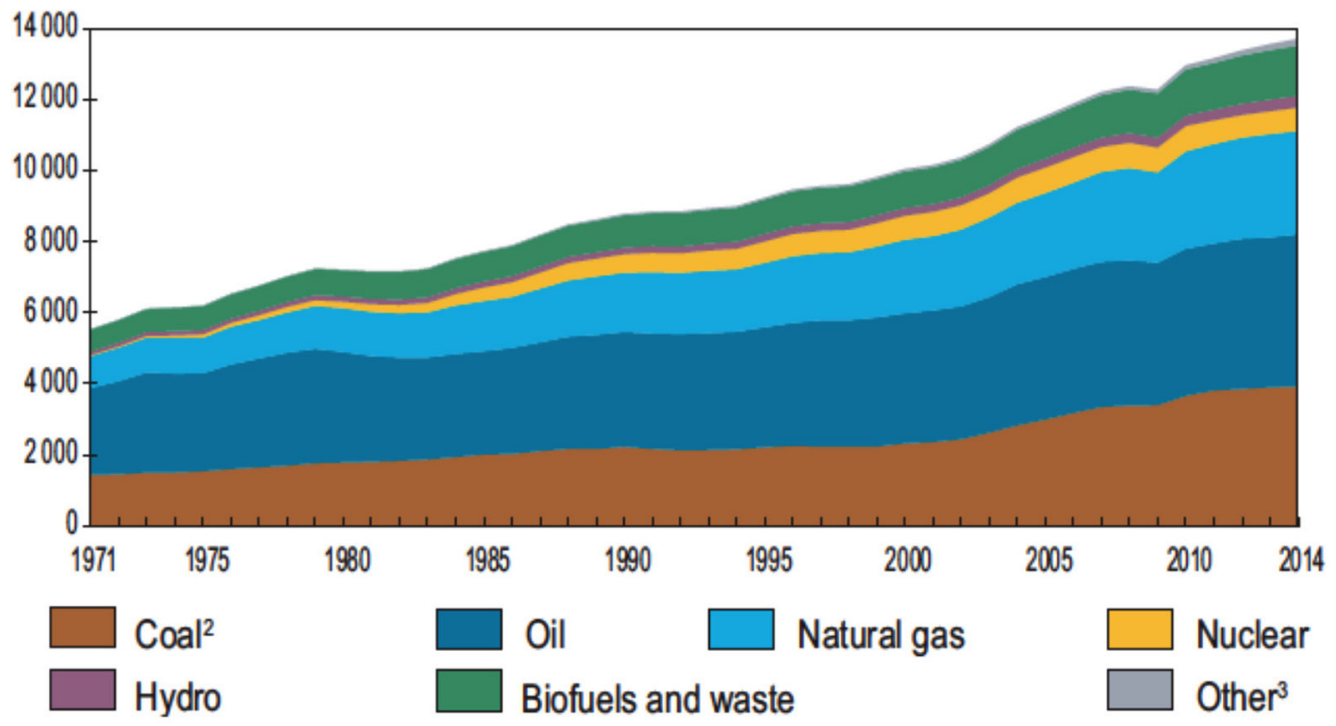

Fig. 2. - World ${ }^{1}$ total primary energy supply (TPES) from 1971 to 2014 by fuel (Mtoe). ${ }^{1}$ World includes international aviation and international marine bunkers. ${ }^{2}$ In these graphs, peat and oil shale are aggregated with coal. ${ }^{3}$ Includes geothermal, solar, wind, heat, etc. (Courtesy of IEA.)

1973

Biofuels and waste

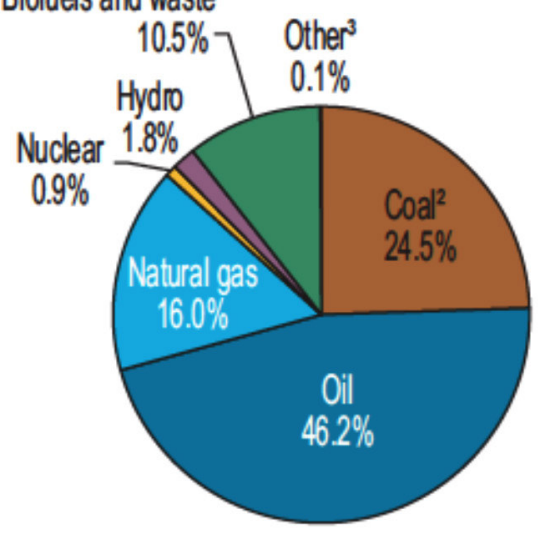

6101 Mtoe
2014

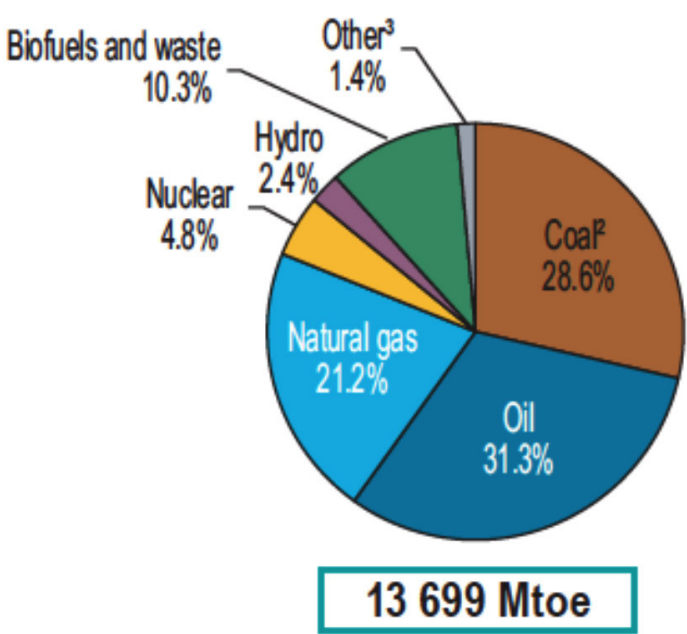

Fig. 3. - 1973 and 2014 fuel shares of TPES. (Courtesy of IEA.) 


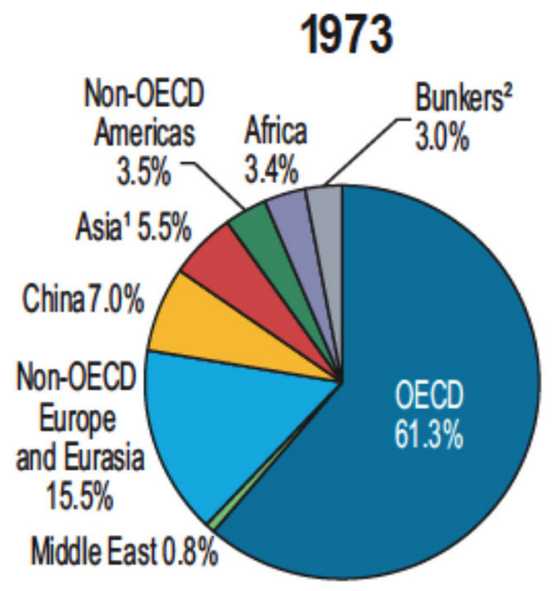

6101 Mtoe

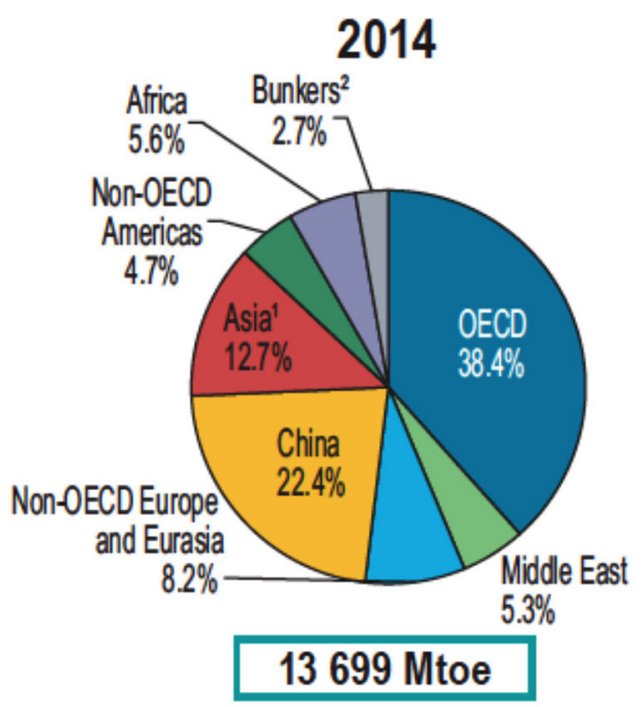

Fig. 4. - 1973 and 2014 regional shares of TPES. ${ }^{1}$ Asia excludes China and OECD countries of Asia. ${ }^{2}$ Includes international aviation and international marine bunkers. (Courtesy of IEA.)

during the last 43 years: more than $80 \%$ of the global supply is coming from fossil fuels. Oil is still the most important primary energy source, even if there has been an important share decrease, while gas and coal increased their share. The dip generated by the recent economic crisis with the growth going back to its "pre-crisis" trend is also shown.

Figure 4, taken from the same IEA publication [2], shows the clear geographic shift of the energy use from the OECD countries to Asia and China, separately considered, reflecting the economic growth that the world has been experiencing in recent years.

Figures 5 and 6, taken from the IEA publication "Key World Energy Statistics" 2016 [2], are related to the global electricity production: again, the dip generated by the recent economic crisis is evident with its growth going back to its "pre-crisis" trend. It is important to note that while the primary-energy demand doubled, the electricity production almost quadrupled in the same period: about two thirds of the electricity production now comes from fossil fuels, with coal, that even increased its share from 1973, being by far the most important source. Oil almost disappeared from electricity production, being now mostly dedicated to chemical industry and transportation, while natural gas almost doubled.

Hydro production decreased its share, but almost tripled its absolute production compared to 1973. Until the Fukushima accident, nuclear and hydro production were about equally sharing the remaining world electricity production; nuclear production is now about two thirds of the hydro production, with the remaining global share being mostly covered by the "new renewables" (mostly wind and solar).

The total final energy consumption in the OECD countries is almost equally divided into the three main sectors: industry, transport and "other sectors" (residential, 


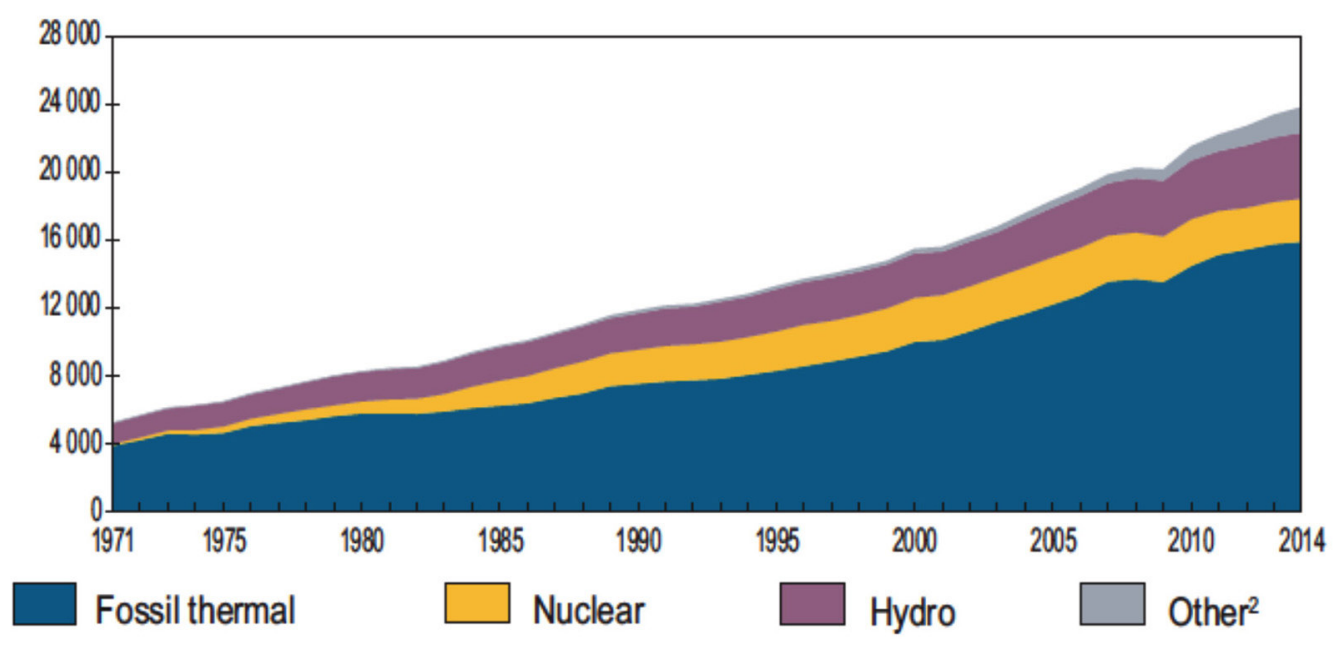

Fig. 5. - World electricity generation ${ }^{1}$ from 1971 to 2014 by fuel (TWh). ${ }^{1}$ Excludes electricity generation from pumped storage. ${ }^{2}$ Includes geothermal, solar, wind, heat. (Courtesy of IEA.)

commercial and public services, agriculture/forestry, fishing and non-specified). A minimal part of the energy final consumption goes to the so-called non-energy use (fuels that are used as raw materials in the different sectors and are not consumed as a fuel or transformed into another fuel. Non-energy use also includes petrochemical feedstocks).

1973

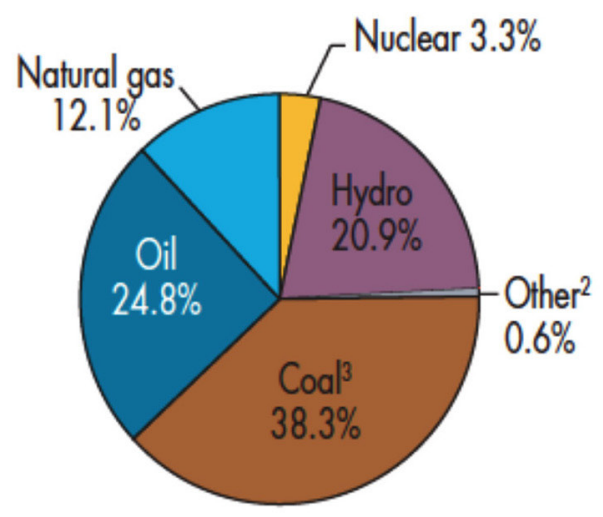

$6131 \mathrm{TWh}$
2014

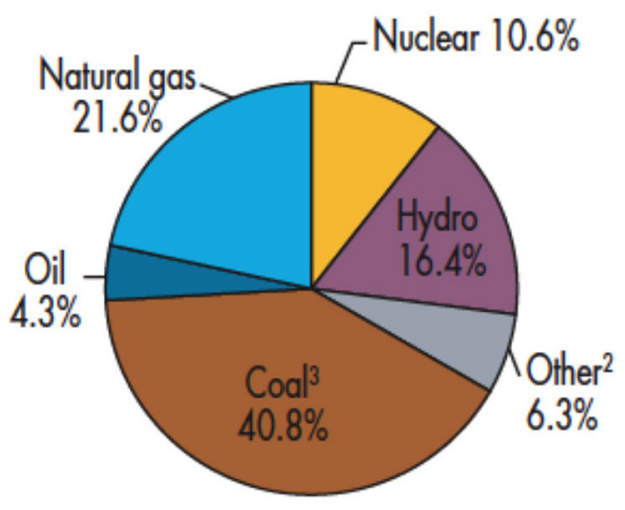

23816 TWh

Fig. 6. - 1973 and 2014 fuel shares of electricity generation. (Courtesy of IEA.) 
Though well known, it is important to underline that transportation depends worldwide on oil, with shares well over $90 \%$ everywhere.

Let us now introduce two new energy indicators: the energy intensity of a country and the electric energy intensity.

The energy intensity, Ei, is defined as the primary energy demand of a country over its Gross Domestic Product (GDP); given the economic inflation, a reference year is needed.

$\mathrm{Ei}$ is an indication of the energy efficiency of a nation's economy, even if it is a complex indicator and depends on several parameters:

- The higher the technological developments, the more efficient is the energy use.

- Heavy industry requires more energy.

- Colder countries require more energy for heating.

- Larger countries require more energy for transportation.

Despite the above mentioned limits, it is observed that Ei grows in emerging economies and decreases with de-industrialization and service sector (tertiary) growth.

The electric energy intensity is defined as the electricity demand of a country over its GDP. It is very similar to Ei but shows an opposite behaviour: the optimal use of electricity induces an increase in productivity and therefore energy savings in total energy.

We have been talking about global energy consumption, but we should not forget that the energy consumption is very far from being equally distributed on our planet: there are places on Earth where the equivalent energy consumption is well over 6 Mtoe per capita, while others where it is not much different from the energy consumption of Early Man.

Africa, having about $14 \%$ of the world population, has only $3 \%$ of the world electricity consumption. South Africa, having about $5 \%$ of the African population, needs about half of the total African electricity consumption. Excluding northern and southern African countries, the main energy source for the remaining African population is wood.

IEA evaluates [4] that about 1.3 billion people on Earth live without electricity and 2.7 billion live without clean cooking facilities (fuels and stoves that do not cause air pollution in houses). As we have seen, access to electricity and to energy in general, is considered to be an essential requirement for human development. IEA evaluates that investments of about $35 \$$ billion/year would bring energy access to the whole world population. For comparison, Germany and Italy together spend every year more than this amount of money to subsidize the RES deployment.

As we have seen, more than $80 \%$ of the world primary energy demand is covered by fossil fuels: does this energy system have any impact on the environment and on men's health? May it go on forever?

I think there are three main limits for the energy system:

- The combustion of fossil fuels generates greenhouse gases (GHG) that have consequences on the climate of our planet. 
- The combustion is also generating polluting emissions like nitrogen and sulphur oxides, particulate matter, carbon monoxide and others that may have an impact on men's health and environment.

- Fossil fuels are by definition finite resources that, sooner or later, will come to an end: what will come next?

The order of this list is just for the sake of this presentation and does not necessarily reflect any priority order. Each single point will now be better specified.

The oxidation of fossil fuels $\mathrm{C}-\mathrm{H}$ bonds generates water and carbon dioxide: they are both necessary elements for life on our planet but the latter is also a GHG (also water vapour is a powerful $\mathrm{GHG}$ ).

As an example let us consider the methane combustion:

$$
\mathrm{CH}_{4}+2 \mathrm{O}_{2} \rightarrow \mathrm{CO}_{2}+2 \mathrm{H}_{2} \mathrm{O}
$$

Simple considerations on molecular weights of the different compounds show that out of $1 \mathrm{~kg}$ of methane, almost $3 \mathrm{~kg}$ of carbon dioxide are generated.

The average temperature of our planet is set by the equilibrium between the incoming radiative energy from the Sun and the outgoing infrared radiation: fig. 7 shows the spectra of the solar incoming energy into our planet and the infrared outgoing energy. They are very well decoupled: the atmosphere is almost transparent to the incoming energy while it is much more absorbent for the outgoing energy. As a result, the mean global temperature of the Earth is about $33^{\circ} \mathrm{C}$ higher than it would be without the atmosphere (i.e. without the natural greenhouse gases present in the atmosphere) and this makes life possible on our planet the way we know it. More than two thirds of the total greenhouse effect on our planet (i.e. two thirds of the $33^{\circ} \mathrm{C}$ temperature increase) are coming from the water vapour that is [5], as shown in fig. 7, the most important GHG in or planet, while carbon dioxide is contributing with about $20 \%$ of the total temperature increase.

The greenhouse radiation forcing of each single gas is well known and the green house theory tells us that a doubling of the carbon dioxide concentration in our atmosphere would give rise to a global temperature increase of about $1^{\circ} \mathrm{C}$ "if the rest is kept firm". Keeping all the rest firm means that we assume there are no feedbacks on our planet.

Climate change feedbacks are important in understanding the climate evolution because feedback processes may amplify or diminish the effect of each climate forcing, as the doubling of carbon dioxide concentration in our atmosphere, and so play an important role in determining the future climate state. Feedbacks may be positive or negative: a positive feedback is, for instance, the increase of the amount of water vapour in the atmosphere with temperature, which in turn leads to further warming. A negative feedback comes from the Stefan-Boltzmann law: the amount of heat radiated from the Earth into space changes with the fourth power of the temperature of the atmosphere.

Clouds are a very important feedback and warming is expected to change their distribution and type. Clouds reflect infrared radiation back to the planet surface, having 


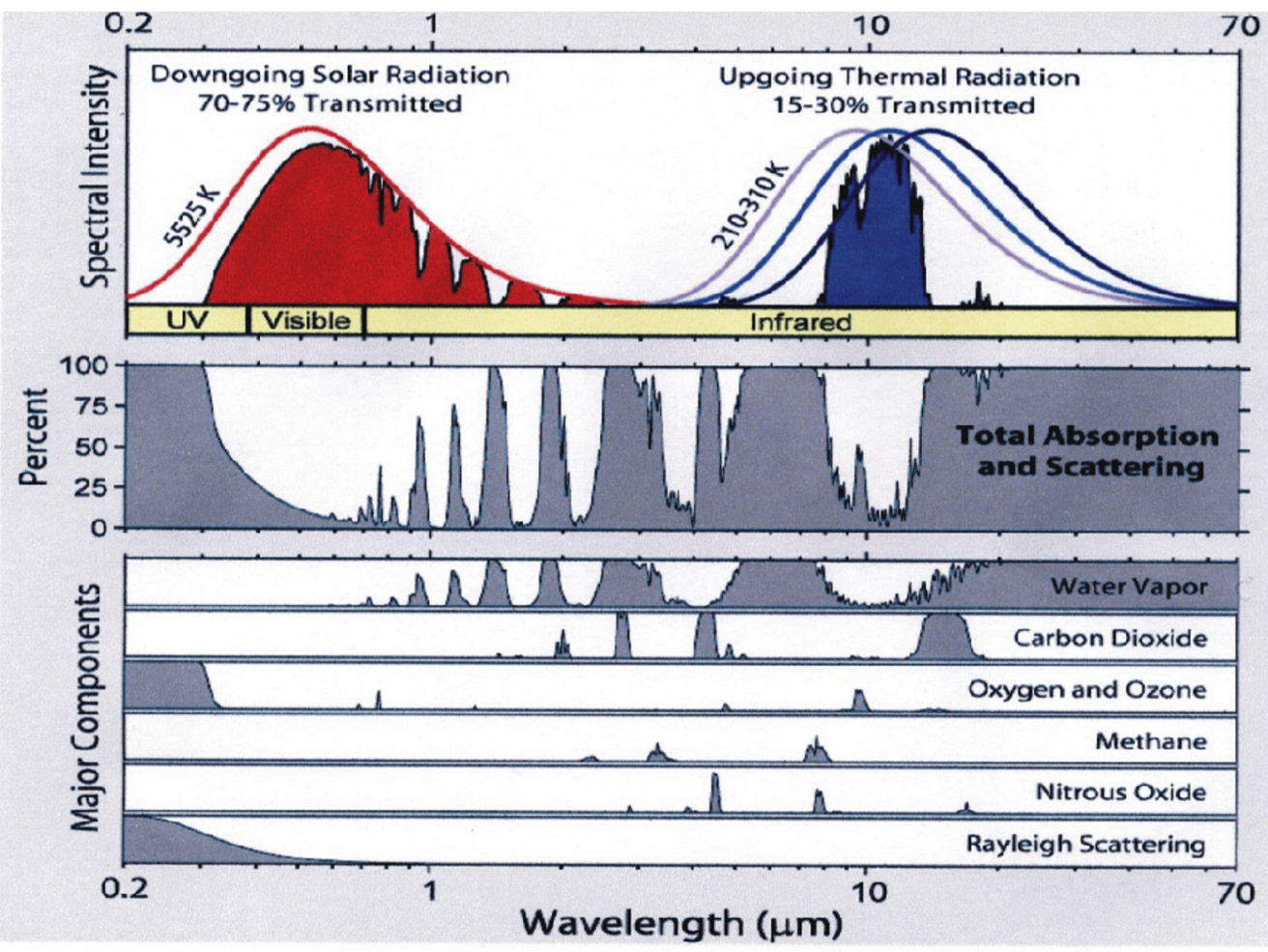

Fig. 7. - Radiation transmitted by the atmosphere.

a warming effect; at the same time clouds reflect sunlight and emit infrared radiation to space, having a cooling effect. Whether the net effect is warming or cooling depends on details such as the type and altitude of the cloud. High clouds tend to trap more heat and therefore have a positive feedback, low clouds normally reflect more sunlight having a negative feedback. According to the last IPCC report [6], cloud feedbacks continue to be the largest uncertainty in the Global Circulation Models (GCMs) that are built to simulate the complex behaviour of our atmosphere considering all possible feedbacks. According to GCMs, the response to our atmosphere to a doubling of carbon dioxide concentration would likely be a temperature increase between $1.5^{\circ} \mathrm{C}$ and $4.5^{\circ} \mathrm{C}$.

The discussion about climate change is not on the well-known GHG theory but on how the complex climate system may respond to an increase of the carbon dioxide forcing considering all known feedbacks.

Let us now come to the polluting emissions generated by the fossil fuels combustion that may have a negative impact on human health and on the environment. We are talking about nitrous or sulphur oxides, generally indicated by $\mathrm{NO}_{x}$ or $\mathrm{SO}_{x}$, Particulate Matter, indicated by $\mathrm{PM}_{x}$, where $x$ represents the maximum size in microns of the particulate we are referring to, ozone, carbon monoxide, $\mathrm{CO}$, generated by an incomplete combustion, and other compounds. 


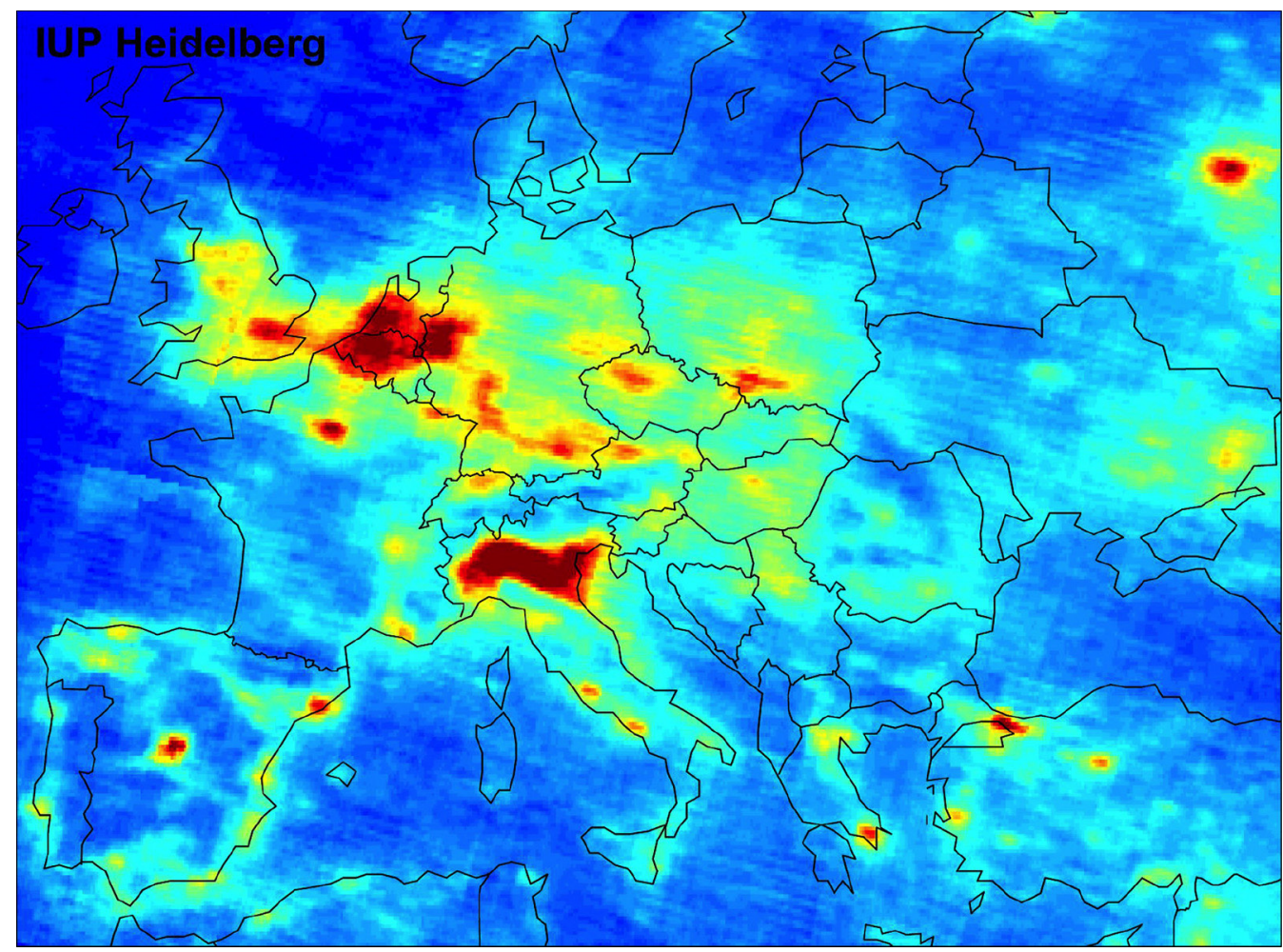

Fig. 8. - European mean tropospheric nitrogen dioxide $\left(\mathrm{NO}_{2}\right)$ vertical column density (VCD) between January 2003 and June 2004, as measured by the SCIAMACHY instrument on ESA's Envisat. Image produced by S. Beirle, U. Platt and T. Wagner of the University of Heidelberg's Institute for Environmental Physics. (Courtesy of T. Wagner.)

Figure 8 shows how the $\mathrm{NO}_{2}$ concentration is linked to human emissions: high levels are evident in large areas like the Netherlands and the Po valley, where concentration is high also because of little exchange with the atmosphere, and over large cities like London, Paris, Madrid and, in Italy, Roma and Naples (Milan is hidden in the middle of the Po valley).

Another very evident effect of atmospheric pollution is shown in fig. 9.

Epidemiologic studies on health effects caused by these polluting emissions are not easy but the harms originated by these compounds are becoming more and more evident as shown in fig. 10 and discussed in recent studies by the World Health Organization (WHO): globally, almost 7 million deaths were attributable to the joint effects of household (HAP) and ambient air pollution (AAP) in 2012 [7].

In the next days there will be specific presentations on this subject that will show the methodology applied to populations to point out and clarify what health effects are produced by such emissions. 


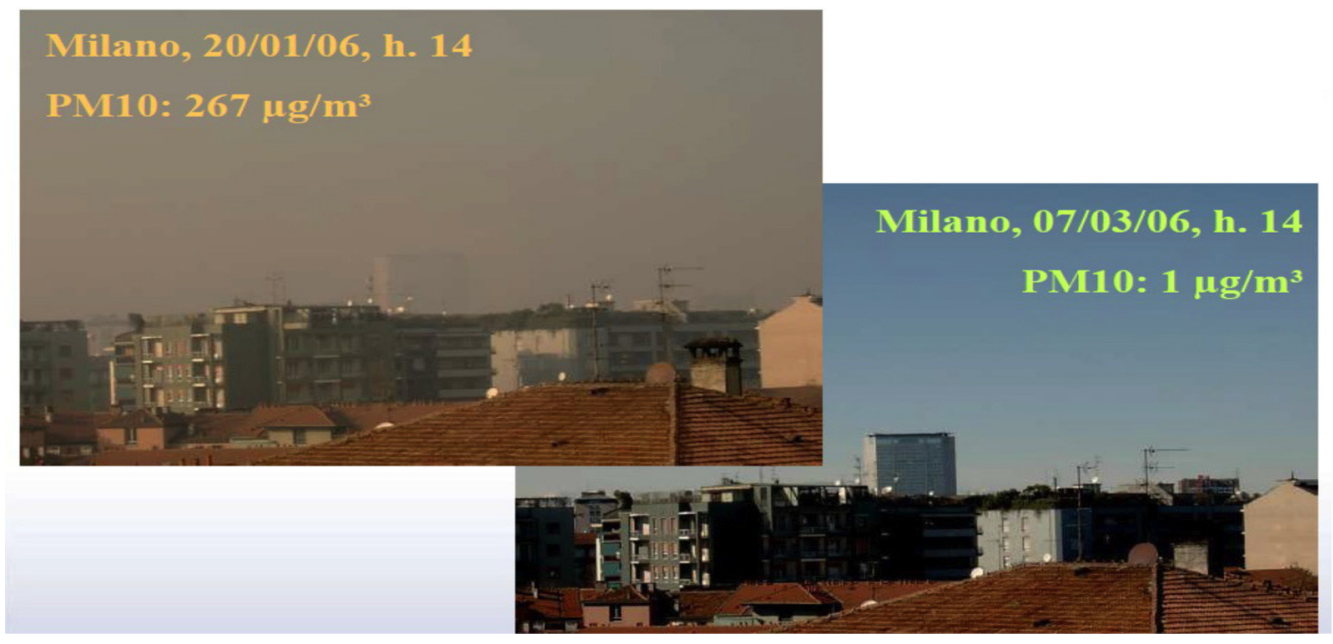

Fig. 9. - Visibility in Milan from the same observation point in days with different PM10 atmospheric concentrations. (Courtesy of Dr. Lazzarini, ARPA Lombardia.)

Last but not least: the fossil fuel sources that, as we have seen, cover nowadays more than $80 \%$ of the global primary energy demand, are limited resources and sooner or later they will run out.

Hubbert, an american geologist and geophysicist who worked at the Shell research lab in Houston, is known for his studies on the size of oil fields. He predicted that, for

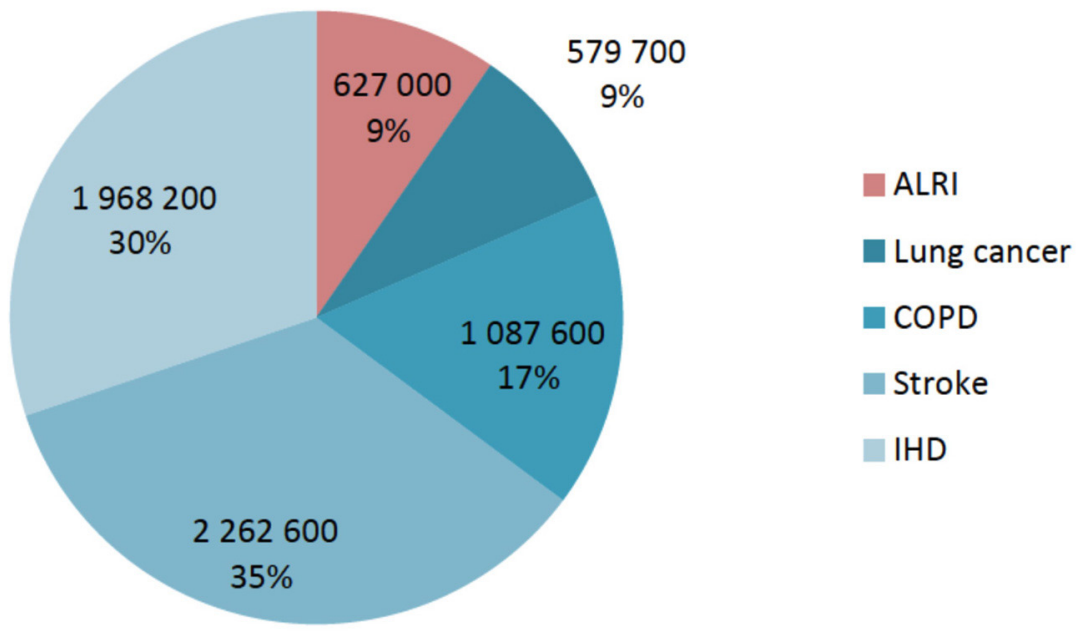

Fig. 10. - Deaths attributable to the joint effects of HAP and AAP in 2012, by disease. HAP: household air pollution; AAP: ambient air pollution; ALRI: acute lower respiratory disease; COPD: chronic obstructive pulmonary disease; IHD: ischaemic heart disease [7]. (Courtesy of WHO.) 


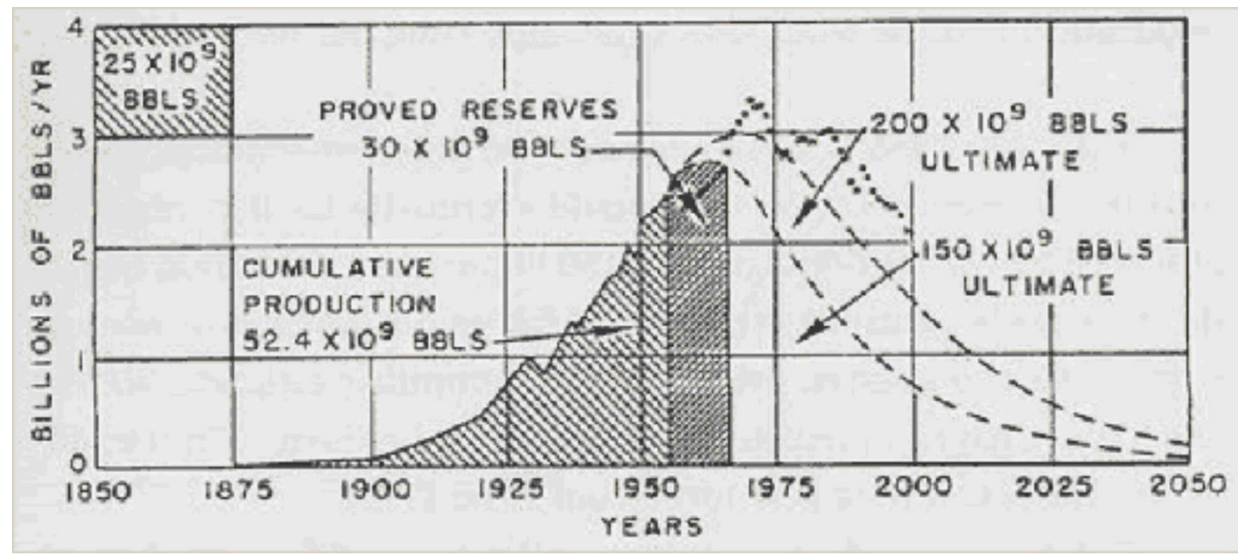

Fig. 11. - Picture taken from "Nuclear energy and the fossil fuels", M. King Hubbert, June 1956, showing the forecast of the United States overall petroleum production.

any given geographical area, from an individual oil field to the planet as a whole, the rate of petroleum production of the reserve over time would resemble a bell curve. Based on his theory, he presented a paper [8] at the 1956 meeting of the American Petroleum Institute in San Antonio, Texas, which predicted that the overall petroleum production would peak in the United States, excluding Alaska, between 1965 and 1970, as shown in fig. 11. At first his prediction received much criticism; Hubbert became famous when his prediction proved correct in 1970 .

In 1974, Hubbert projected that global oil production would peak in 1995 "if current trends continue". Various subsequent predictions have been made by others as trends have fluctuated in the intervening years. Fortunately technologies evolve: new oil reserves can be found and known oil reserves may become economically exploitable. As an example, the US oil production, after the peak in the seventies and a subsequent decrease, came back with a steep rise.

The red curve of fig. 12 [9] is showing that Hubbert was correct in his projection relative to the US production excluding Alaska. When Alaska production is considered together with offshore drilling and the recent tight or the so called non-conventional production, the overall US oil production is nowadays at the same level of the peak reached in the seventies.

The message is that we are using limited resources but they will not finish tomorrow. This is a delicate subject where not only technical considerations but also economic and geopolitical considerations come in: there will be a dedicated presentation during the coming week on this issue.

As Hubbert was saying: "Energy is essential for all organic and inorganic activities: history of human evolution reflects history of mankind ability to control and transform Energy". The discovery of fire, that allowed Man to convert the chemical energy of wood into light and heat, was maybe the first and the most important discovery. Up 


\section{U.S. oil production by source}

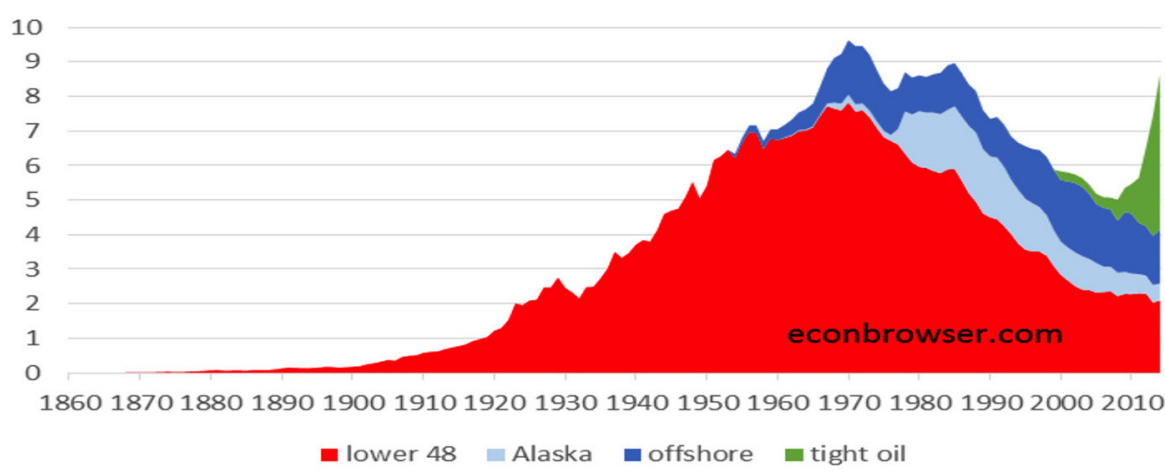

Fig. 12. - US oil production up to a few years ago. (Courtesy of Prof. Hamilton.)

to the steam engine, that initiated the industrial revolution, mankind fulfilled its energy needs thanks to agriculture and the exploitation of the original renewable sources. The industrial revolution allowed fossil fuels to strongly enter and shape our development: diffused and cheap energy allowed to replace human labor and activities impossible until that time became common.

For comparison, let us consider that during the Roman empire, a slave eating about 2000-2500 kcal/day, could produce a work output around 300-400 Wh/day, equal to about 100 grams of oil: every european citizen, who now consumes about $10 \mathrm{~kg}$ of oil a day, is exploiting the job of 100 to 150 slaves.

As a consequence, the energy demand increased to a level never reached before, as simply synthesized in fig. 13. We are nowadays on the fossil fuel peak: it is not clear

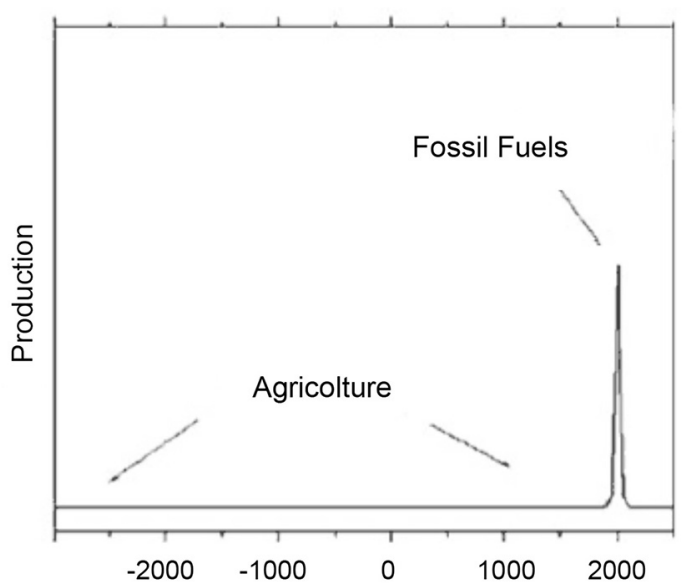

Fig. 13. - Historical mankind energy sources. 
whether we are just before, exactly on, or just after the peak, but we have seen that there are important reasons to start thinking about what will come next.

This is what this school is about.

\section{REFERENCES}

[1] IEA, World Energy Outlook (International Energy Agency) 2004.

[2] IEA, Key world energy statistics (International Energy Agency) 2016.

[3] BP, BP Statistical Review of World Energy, June 2016.

[4] IEA, World Energy Outlook (International Energy Agency) 2011.

[5] Lacis A. et al., Atmospheric $\mathrm{CO}_{2}$ : Principal Control Knob Governing Earth's Temperature, Science, 330 (2010) 356.

[6] Stocker T. F. et al. (Working Group I of the IPCC), Climate Change 2013 - The Physical Science Basis (Intergovernmental Panel on Climate Change IPCC) 2013.

[7] WHO, Burden of disease from the joint effects of Household and Ambient Air Pollution for 2012 (World Health Organization) 2016.

[8] Hubbert M. K., Nuclear Energy and the fossil fuels publ. No. 95 (Shell Development Company, Houston) 1956.

[9] Hamilton J. D., The Changing Face of World Oil Markets (Department of Economics, University of California, San Diego) 2014. 